\title{
Aphid problems increase on ornamentals
}

\author{
Stacy L. Vehrs $\square \quad$ Michael P. Parrella
}

\section{Aphids, and the green peach and melon aphids in particular, have dramatically increased their effect on ornamental crops over the past few years. An aphid-specific fun- gus may be useful for biological control under the right environ- mental conditions.}

Aphids are economically important pests on many ornamental crops. Under the optimal environmental conditions of the greenhouse, parthenogenetic (asexual) and viviparous (live-bearing) reproduction can continue year-round. In such circumstances, large populations are quick to develop.

Aphids damage crops directly, wilting and distorting leaves and flowers as they feed, but they also cause a number of other problems. The physical presence of a large number of aphids can be a cause for concern, and the honeydew they excrete as they feed promotes the growth of black sooty molds, which in turn reduce the crop's photosynthesis as well as its aesthetic value. Dust, dirt, and skins shed in molting adhere to the viscous substance, making plants unsightly. Furthermore, aphids transmit several plant viruses.

Because many ornamental crops have little tolerance for damage, growers need to identify aphid populations early and take appropriate control measures. The need for early control has resulted in the sometimes unnecessary prophylactic use of chemicals for aphid control in greenhouses and nurseries. The repeated heavy use of insecticides is clearly inconsistent with integrated pest management, a concern for the environment, and a concern for the health and safety of agricultural workers.

Furthermore, two polyphagous aphid species have developed pesticide resistance (green peach aphid and cotton or melon aphid), and they attack many ornamental plants. Aphids are causing increasing problems in California greenhouses and nurseries. The prospect for continued conventionalchemical control of aphids appears bleak. Insecticide resistance, a lack of new insecticide registrations, the loss of existing materials, and tougher laws governing pes- ticide use make any reliance on chemical control a risky proposition.

It is time to develop an integrated approach to aphid control in California ornamentals production. With that as ourultimate goal, we initiated studies to identify the aphid species causing the most problems in ornamental production, and to evaluate the control potential of Verticillium lecanii, an aphid-specific fungus.

\section{Survey: aphids in ornamental crops}

Our survey concentrated on aphids found on greenhouse ornamental crops, mostly chrysanthemums, Dendranthema grandiflora (Tzvelev), and other composite flowers. We took specimens from commercial ornamentals greenhousesin several counties each season - spring, summer, fall, and winter

TABLE 1. Important aphid species on ornamental crops in California, 1987-1989

\begin{tabular}{|c|c|}
\hline Species & Crop \\
\hline Myzus persicae & Chrysanthemums \\
\hline Aphis gossypii & Chrysanthemums \\
\hline Cinara spp. & Juniper \\
\hline Lipaphis erysimis & Dusty Miller \\
\hline Macrosiphum & \\
\hline euphoribae & Rose \\
\hline Hyperomyzus & \\
\hline $\begin{array}{l}\text { lactucae } \\
\text { Rhopalosiphum }\end{array}$ & Dusty Miller \\
\hline $\begin{array}{c}\text { nymphae } \\
\text { Wahqreniella }\end{array}$ & Calla lily \\
\hline nervata & Rose \\
\hline Brevicoryne & \\
\hline brassicae & Flowering cabbage \\
\hline Aulacorthum & \\
\hline circumflexum & Lilies \\
\hline
\end{tabular}

TABLE 2. Number of live and infected wingless adult female $A$. gossypi aphids 3 and 6 days after applying two concentrations of $V$. lecanii, an aphid-pathogenic fungus*

\begin{tabular}{|c|c|c|c|c|}
\hline \multirow[t]{2}{*}{$\begin{array}{l}\text { Treatment } \\
\text { Live }\end{array}$} & \multicolumn{2}{|c|}{$\begin{array}{c}3 \text { days } \\
\text { post- } \\
\text { treatment } \\
\text { Live } \\
\text { Infected }\end{array}$} & \multicolumn{2}{|c|}{$\begin{array}{c}6 \text { days } \\
\text { post- } \\
\text { treatment } \\
\text { Infected }\end{array}$} \\
\hline & & $\ldots .$. & $m / .$. & \\
\hline 0.0 (control) & 100 & 0 & 94 & 0 \\
\hline $2.4 \times 10^{5}$ & 94 & 6 & 8 & 91 \\
\hline $2.4 \times 10^{6}$ & 88 & 11 & 0 & 97 \\
\hline
\end{tabular}

* There was a significant association between treatment and infection. Day 3: Pearson Chi-squared $=$ $11.44, \mathrm{df}=2, \mathrm{P}=0.003$. Day 6: Pearson Chisquared $=256.9, d f=2, P<0.0001$.

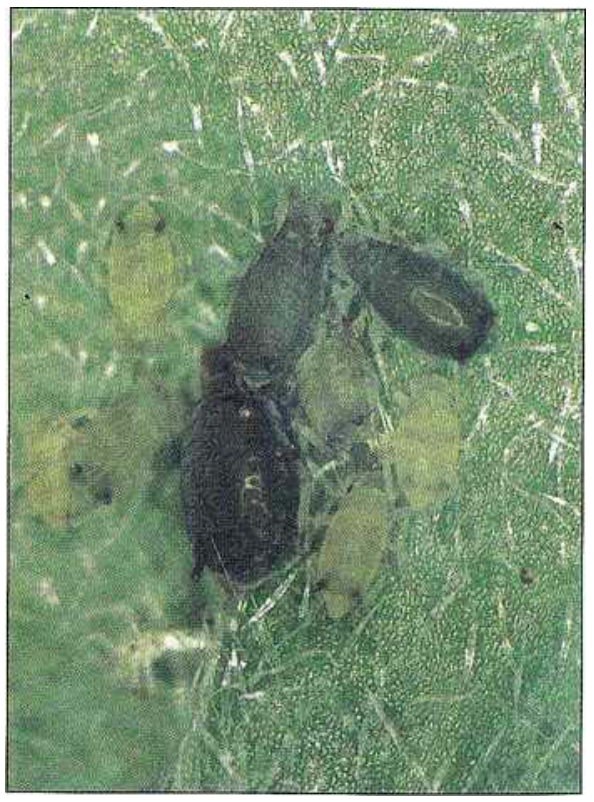

Aphis gossypii (the cotton or melon aphid) is on the increase as a pest of ornamentals in California.

- beginning in February, 1988, and ending in July, 1989. Sacramento, San Mateo, Monterey, Santa Barbara, and San Diego counties are home to the state's major chyrsanthemum growing areas, and all were included in our survey.

We took one or more samples from each county and from multiple sites within some counties. We collected specimens with a camel's-hair brush and placed them in 70\% ethanol. For identification, we made temporary mounts using Hoyer's medium. Standard keys were used to identify specimens, and we sent those we could not identify to taxonomists at the California Department of Food and Agriculture.

The two most commonly found aphid species by far were the green peach aphid, Myzus persicae (Sulcer), and the cotton or melon aphid, Aphis gossypii Glover (table 1). Both species infested a wide variety of ornamental plants in all surveyed counties. On chrysanthemums and other composite flowers, $M$. persicae was the species mostoften found colonizing commercial crops.

\section{Verticillium lecanii}

With the green peach and cotton or melon aphid as the major target of our control efforts, we evaluated the fungus Verticillium lecanii. This material has shown promise in European greenhouses, and there is a possibility it will be registered in the United States.

Verticillium lecanii is a deuteromycete fungus that is pathogenic on several insects and other organisms. It occurs naturally among dense populations of several green- 
house pests, including the greenhouse whitefly, Trialeurodes vaporariorum (Westwood), and many aphids, including A. gossypii and $M$. persicae.

Two spore strains of $V$. lecanii are available commercially in Europe to control these pests. The two are a small-spore strain (Mycotal) most effective for whitefly control and a large-spore strain (Vertalec) most effective for aphid control.Our study objectives were to develop a simplified way of producing spores and to test the control effectiveness of fresh spores on aphids in California, where little research has addressed this insect pathogen.

\section{Spore production and harvest}

We produced Verticillium lecanii conidia (spores) under a constant temperature of $21^{\circ} \mathrm{C}$, and used potato dextrose agar for the culture medium. To maintain high infectivity, we re-isolated the cultures frequently from infected aphids. The initial culture was started by germinating spores from a commercial sample of Vertalec.

To test the efficacy of our culture, we performed two experiments using different spore concentrations. The first was a laboratory bioassay to determine the potential for infection at different concentrations; the second, a greenhouse trial at UC Riverside to test actual infection under more realistic greenhouse conditions.

We harvested spores from the agar plates by scraping the top of the mycelia with a metal spatula and rinsing with a phosphate buffer containing a wetting agent. We then filtered the rinse solution to remove agar and mycelia fragments. Using a hemocytometer and a compound microscope, we counted the number of spores present per milliliter. Serial dilution then yielded the test concentrations.

\section{Laboratory bioassay}

Each replicate consisted of one adult female apterous $A$. gossypii placed on an excised chrysanthemum leaf in a petri dish lined with moist filter paper. The treatments included two spore concentrations $\left(2.4 \times 10^{6}\right.$ and $2.4 \times 10^{5}$ spores $/ \mathrm{ml}$ ) and a buffer control, and were applied with a hand-held misting bottle. We then placed the petri dishes in an environmental chamber where they could achieve optimal conditions for spore germination.

We counted the live, dead, and fungusinfected aphids 3 and 6 days posttreatment. We only included the original adult female aphids in our counts. By day 3 the infection had started, and by day 6 nearly all aphids in the spore treatments were dead (table 2). The laboratory bioassay showed that our $V$. lecanii culture had a high potential for infecting $A$. gossypii. Both tested concentrations were effective in initiating infection.

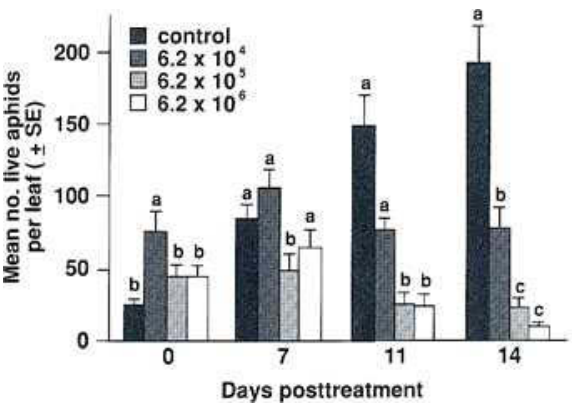

Fig. 1. Efficacy of Verticillium lecanii for contro of Aphis gossypii on chrysanthemums. The data are represented as mean number of live aphids per leaf $( \pm S E)$ vs. days posttreatment. Data were transformed $\log _{e}(y+1)$ before ANOVA. Untransformed data are presented here. Means on the same day followed by the same letter are not significantly different (Duncan's New Multiple Range Test at alpha = 0.05).

\section{Greenhouse trial}

For our greenhouse trial, we used 31/2-weekold chrysanthemums (cultivar, Florida Marble,) that were about $25 \mathrm{~cm}$ tall. The plants were naturally infested with $A$. gossypii. Our completely randomized design included 10 plants per treatment, each planted in its own $15 \mathrm{~cm}$ pot. This time we tested three spore concentrations $\left(6.2 \times 10^{6}\right.$, $6.2 \times 10^{5}$, and $6.2 \times 10^{4}$ spores $/ \mathrm{ml}$ ) and a buffer control. Treatments were applied to runoff - approximately $50 \mathrm{ml}$ per plant using a 1gallon hand sprayer at a pressure of 40 psi.

Temperature and relative humidity in the greenhouse ranged from $22^{\circ}$ to $32^{\circ} \mathrm{C}$ and 30 to $100 \%$. We kept the humidity high near the plants by misting the plants lightly from above in the afternoon, when the ambient relative humidity was lowest. To sample, we counted all aphids on one upper and one lower leaf of each plant. A pretreatment count of live aphids was made for each of the three treatments and the buffer control. We then counted live and infected aphids 7, 11, and 14 days posttreatment.

The control populations increased dramatically during theexperiment, but treated populations remained constant or declined (fig. 1). The $6.2 \times 10^{4}$ spores $/ \mathrm{ml}$ treatment began with more aphids, but populations had not increased at the end of the trial. The number of live aphids per leaf in the higherconcentration treatments declined as the trial progressed.

The percentage of infected aphids increased directly with the spore concentration: the highest concentration had the highest infection rate (fig. 2). Since this is a disease-causing organism, even the lowest concentration would have continued to approach $100 \%$ infection, given a continued optimalenvironment. The timetaken to reach maximum infection depends on the amount of initial inoculum, which we could increase

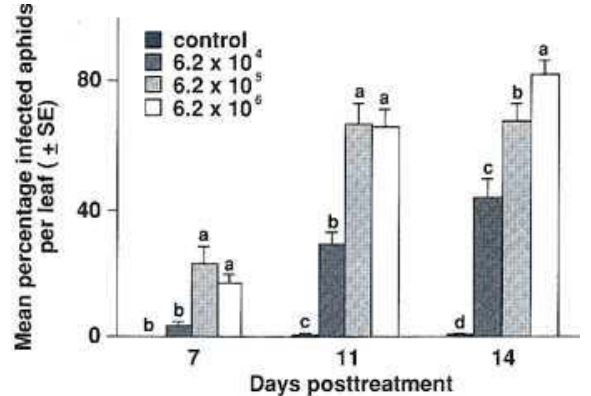

Fig. 2. Efficacy of Verticillium lecanii for control of Aphis gossypii on chrysanthemums. The data are represented here as mean percentage of infected aphids per leaf ( \pm SE) vS. days posttreatment. Arcsin squareroot $(y+1)$ transformation was performed on data before ANOVA. Untransformed data are presented here. Means on the same day followed by the same letter are not significantly different (Duncan's New Multiple Range Test at alpha $=0.05$ ) .

by using a greater spore concentration. A few individuals in the control showed signs of infection, resulting in the small percentage of mortality shown in fig. 2 . The control group infections may indicate immigration of infected aphids into the control plants.

\section{Conclusion}

Because of the environmental requirements for $V$. lecanii, its use may be limited to humid propagation areas with moderate temperatures. Two such areas are rooting benches and shade-cloth covered areas used to induce inflorescence in chrysanthemums. Under these specific conditions, Verticillium lecanii has the potential to eliminate the need for insecticideapplications for aphid control.

Since it is not a conventional chemical control, V.lecanii requires no re-entry period and is safe both to workers and to the environment. Each strain is highly host-specific, making it compatible with other biological control organisms. Although many fungicides used to control plant pathogens may be incompatible, others have little impact on V.lecanii, and you could time applications to control both types of pest in the greenhouse. Commercial registration of this product in California would lead to widespread use.

Stacy L. Vehrs is Staff Research Associate, UC Riverside, stationed at Kearney Agricultural Center; and Michael P. Parrella, formerly with UC Riverside, is now Associate Professor of Entomology at UC Davis. The authors extend their appreciation to J. A. Bethke for technical support, and thank the California Association of Nurserymen, the California State Florists Association, and the American Floral Endowment for financial support. Yoder Brothers, Inc. and the California Plant Company donated plant material for these studies. The authors also thank $T$. Kono, California Department of Food and Agriculture, for helping with aphid identification. 